\title{
Enhancement of Photoluminescence Lifetime of ZnO Nanorods Making Use of Thiourea
}

\author{
Erdal Sönmez ${ }^{1,2}$ and Kadem Meral' ${ }^{2,3}$ \\ ${ }^{1}$ Department of Physics, Faculty of Education, Atatürk University, 25240 Erzurum, Turkey \\ ${ }^{2}$ Advanced Materials Research Laboratory, Department of Nanoscience \& Nanoengineering, Graduate School of Natural and \\ Applied Sciences, Atatürk University, 25240 Erzurum, Turkey \\ ${ }^{3}$ Department of Chemistry, Faculty of Science, Atatürk University, 25240 Erzurum, Turkey
}

Correspondence should be addressed to Erdal Sönmez, esonmez@atauni.edu.tr

Received 7 March 2012; Revised 10 May 2012; Accepted 13 May 2012

Academic Editor: Vo-Van Truong

Copyright ( $\odot 2012$ E. Sönmez and K. Meral. This is an open access article distributed under the Creative Commons Attribution License, which permits unrestricted use, distribution, and reproduction in any medium, provided the original work is properly cited.

\begin{abstract}
We have investigated correlation of photoluminescence lifetime between zinc oxide $(\mathrm{ZnO})$ nanorods and thiourea-doped $\mathrm{ZnO}$ nanorods ( $\mathrm{tu}: \mathrm{CH}_{4} \mathrm{~N}_{2} \mathrm{~S}$ ). Aqueous solutions of $\mathrm{ZnO}$ nanorods were deposited on glass substrate by using pneumatic spray pyrolysis technique. The as-prepared specimens were characterized by X-ray diffraction (XRD), scanning electron microscopy (SEM), and time-resolved photoluminescence spectroscopy (TRPL). The photoluminescence lifetime of $\mathrm{ZnO}$ nanorods and $\mathrm{ZnO}$ nanorods containing thiourea was determined as $\tau=1.56 \pm 0.05 \mathrm{~ns}\left(\chi^{2}=0.9\right)$ and $\tau=2.12 \pm 0.03 \mathrm{~ns}\left(\chi^{2}=1.0\right)$, respectively. The calculated lifetime values of $\mathrm{ZnO}$ nanorods revealed that the presence of thiourea in $\mathrm{ZnO}$ nanorods resulted in increasing the exciton lifetime. In addition to the optical quality of $\mathrm{ZnO}$ nanorods, their exciton lifetime is comparable to the longest lifetimes reported for $\mathrm{ZnO}$ nanorods. The structural improvement of $\mathrm{ZnO}$ nanorods, containing thiourea, was also elucidated by taking their SEM images which show the thinner and longer $\mathrm{ZnO}$ nanorods compared to those without thiourea.
\end{abstract}

\section{Introduction}

Zinc oxide $(\mathrm{ZnO})$ is a wide-band gap $\left(E_{\mathrm{g}} \approx 3.37 \mathrm{eV}\right.$ at $300 \mathrm{~K})$ semiconductor with good carrier mobility and can be doped n-type or p-type. It has many applications in a very important area such as ultraviolet light-emitting diodes and nanolaser [1]. $\mathrm{ZnO}$ shows pronounced excitonic effects at high temperatures $(>300 \mathrm{~K})$ due to its large exciton binding energy $(60 \mathrm{meV})$ [2]. Optically pumped lasing has been successfully demonstrated for the $\mathrm{ZnO}$ nanostructures, which have resulted in the intense attention to $\mathrm{ZnO}$ optical properties [3-21]. For example, the optical properties of $\mathrm{ZnO}$ nanostructures at different morphologies are reported at varying temperatures and the performance-structure relation for $\mathrm{ZnO}$ nanostructures are evaluated for some applications. Further improvement in the quality of $\mathrm{ZnO}$ is necessary to achieve the superior device performance [22]. In this regard, main progress has been made toward the growth of good-quality $\mathrm{ZnO}$ nanostructures for the fabrication of light-emitting diodes [8].
The material quality and optical properties of the nanostructures, such as $\mathrm{ZnO}$, are commonly followed by using the photoluminescence (PL) and time-resolved photoluminescence (TRPL) measurements [23]. Especially, TRPL provides significant information in relation to the exciton lifetime which is an important indicator for the material quality and efficiency of the radiative recombination [6]. It is known that the lifetime is related to the radiative decay of the exciton and various nonradiative processes such as leak by deep-level traps, low-lying surface states and multiphonon scattering $[24,25]$. In this regard, the separation of the radiative recombination and nonradiative processes is difficult [26]. However, the radiative excitation lifetime $\left(k_{r}\right)$ is improved by decreasing the structural defect of $\mathrm{ZnO}$ nanostructures. Therefore, different morphologies of $\mathrm{ZnO}$ nanostructures exhibit very different lifetimes, with some showing very fast decay, while others have decay times as long as comparable to those of good-quality. As a result of these explanations, it is concluded that the morphologies and dimensions of 
$\mathrm{ZnO}$ nanostructures affect the exciton lifetimes $[15,18]$. For example, the high-quality $\mathrm{ZnO}$ single crystals have several nanoseconds exciton lifetime at room temperature [6]. Therefore, the exciton lifetime of $\mathrm{ZnO}$ nanostructures is changed by the controlling of their morphologies and dimensions. The structure of $\mathrm{ZnO}$ is controlled by precious parameters such as the starting zinc compound, chemical composition of solvent, nature of the precipitating agent, $\mathrm{pH}$, temperature, and aging time [27]. In addition to growth conditions, deposition methods of $\mathrm{ZnO}$ onto solid surface play a key role for $\mathrm{ZnO}$ nanostructures. Therefore, different deposition methods have been developed to fabricate a variety of $\mathrm{ZnO}$ nanostructures such as wellknown metal organic chemical vapor $[28,29]$, pulsed laser $[30,31]$, electrochemical deposition techniques $[32,33]$, vapor-liquid, solid $[34,35]$, and wet chemical methods [3638]. In addition to those methods, the important one is chemical spray pyrolysis system which is one of the most elegant methods to the preparation of good-quality $\mathrm{ZnO}$ nanostructures. This method has several advantages over the other methods such as providing short time, being costeffective and template-free [39]. Consequently, a variety of $\mathrm{ZnO}$ nanostructures are easily fabricated by tuning of material growth conditions. If the optimal conditions are determined, various $\mathrm{ZnO}$ nanostructures can be prepared such as nanowires, nanoribbons, tetrapods, and nanorods, which exhibit excellent optical properties [5].

In the present study, the smaller and longer $\mathrm{ZnO}$ nanorods were prepared by doping a little amount of thiourea (tu: $\mathrm{CH}_{4} \mathrm{~N}_{2} \mathrm{~S}$ ) into zinc chloride $\left(\mathrm{ZnCl}_{2}\right)$ solution, $\mathrm{ZnO}$ nanorods with and without thiourea have been deposited on a glass substrates via chemical spray pyrolysis method at different temperatures. The optical and structural properties of $\mathrm{ZnO}$ nanorods have been examined by X-ray diffraction (XRD), scanning electron microscopy (SEM), and timeresolved photoluminescence (TRPL) techniques. The results showed that the exciton lifetime of $\mathrm{ZnO}$ nanorods was increased in the presence of thiourea.

\section{Experimental}

All chemicals were analytical grade and were used without further purification. $\mathrm{ZnO}$ was deposited using spray aqueous solutions by pneumatic spray pyrolysis technique. The solutions, used for the preparation of $\mathrm{ZnO}$ as thin films, were that the first contained $\mathrm{ZnCl}_{2}$ while the second included $\mathrm{ZnCl}_{2}$ and thiourea with molar ratios of $1: 0.25$. The starting solution was atomized at a frequency of $1.63 \mathrm{MHz}$ by an ultrasonic nebulizer and by using dry air. The solution was mixed with magnetic mixer. Mixing process lasted for $20 \mathrm{~min}$. The resultant amounts of each solution are $50 \mathrm{~mL}$. The nozzle-substrate distance was maintained at $10 \mathrm{~cm}$. The deposition temperature (temperature of substrate surface), in the range of $350-550^{\circ} \mathrm{C}$, was varied by using electronic temperature controller (TET-612 temperature controller by product ColdfusionX Electronics) device on the hot plate metallic surface. The temperature of the metallic surface was totally stable throughout the process at 350,450, and $550 \pm 2^{\circ} \mathrm{C}$, respectively. The substrates were not used at temperature above $550^{\circ} \mathrm{C}$ because they were physically being an irreparable disrupted. The substrates are ordinary microscope slides. Before loading into the system, the substrates were washed with detergent and then completely rinsed in methanol, acetone, and deionized water, respectively, and dried in air. Before being sprayed on the substrates they were progressively heated up to the required temperature. The solution flow rate and gas pressure were kept constant at $1 \mathrm{~mL} / \mathrm{min}$. Air was used as the carrier gas supplied by a filtered oil-free compressor. The duration of the film deposition was about $50 \mathrm{~min}$. The color of $\mathrm{ZnO}$ film was white and it had a very good adhesion to glass substrates.

The structural characterization of deposited films structures of $\mathrm{ZnO}$ was carried out by X-ray diffraction (XRD) measurements using a Rigaku D/Max-IIIC diffractometer with $\mathrm{CuK} \alpha 1$ radiation $(\lambda=1.5418 \AA)$, at $30 \mathrm{kV}, 10 \mathrm{~mA}$. The $2 \theta$ range, used in the measurement, was from 100 to 700 in steps of $0.02 \mathrm{~s}^{-1}$. Surface morphology was examined by a JEOL JSM5610 model scanning electron microscope operating at $25 \mathrm{kV}$. Photoluminescence decays, for the exciton lifetime measurements, were carried out with a Laser Strobe Model TM-3 lifetime fluorometer from Photon Technology International. The excitation source consists of a pulsed nitrogen laser/tunable dye laser combination. Pulse width is about 800 ps and has repetition rate up to 20 pulses per second. The samples were excited at $337 \mathrm{~nm}$ nitrogen laser and, then, photoluminescence decays were monitored. The photoluminescence decays were analyzed with the lifetime distribution analysis software (Felix32) from the instrumentsupplying company. The quality of fits was assessed by chisquare $\left(\chi^{2}\right)$ values. Fitting with $\chi^{2}$ not more than 1.5 was taken as acceptable.

\section{Results and Discussion}

Firstly, the morphology of spray-deposited $\mathrm{ZnO}$ nanostructures was investigated as a function of the growth temperature, which is one of the most important experimental factor for the elucidation of nanostructures [27]. For this purpose, $\mathrm{ZnO}$ nanostructures were deposited on the glass substrate-at different temperatures $\left(350,450\right.$, and $\left.550^{\circ} \mathrm{C}\right)$. The results of those experiments showed that elongated hexagonal prisms shaped $\mathrm{ZnO}$ nanostructures have been formed at $550^{\circ} \mathrm{C}$. Therefore, the deposition temperature was optimized as $550^{\circ} \mathrm{C}$ for all sample preparations. Figure 1 illustrates the SEM images of $\mathrm{ZnO}$ deposited onto the glass substrates by the spray pyrolysis process using only $\mathrm{ZnCl}_{2}$ (Figures $1(\mathrm{a})-1(\mathrm{c})$ ) and $\mathrm{ZnCl}_{2}$ containing thiourea additive with a molar ratio of $\mathrm{Zn}: \mathrm{tu}=1: 0.25$ (Figure 1(d)). SEM images demonstrated that the nanorod structures of $\mathrm{ZnO}$ on the glass substrate were formed at $550^{\circ} \mathrm{C}$. Additionally, it can be seen the SEM images (Figure 1) that this deposition temperature is suitable for the formation of $\mathrm{ZnO}$ nanorods without or with thiourea. The addition of thiourea into the $\mathrm{ZnCl}_{2}$ solution drastically influenced the $\mathrm{ZnO}$ nanorods dimensions as seen by the careful investigation of SEM images. The diameter of the $\mathrm{ZnO}$ nanorods was decreased from $1000 \mathrm{~nm}$ to $500 \mathrm{~nm}$, while their lengths increased to about $200 \mathrm{~nm}$ by thiourea doped in the solution. As a result, 


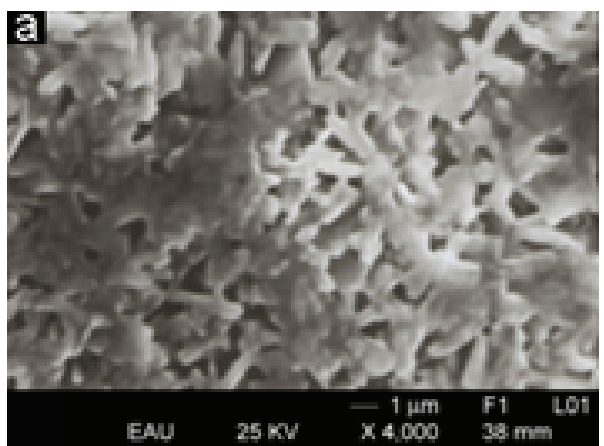

(a)

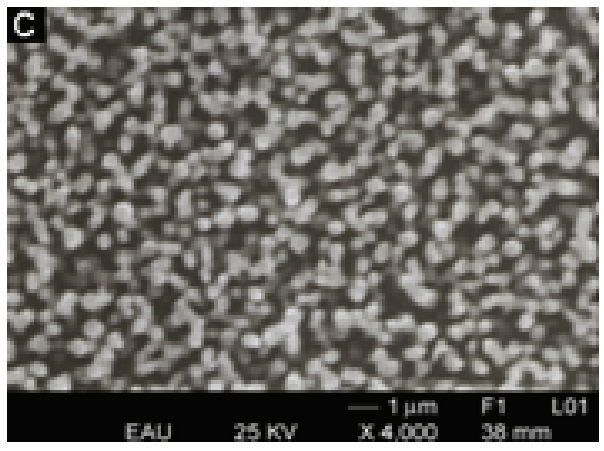

(c)

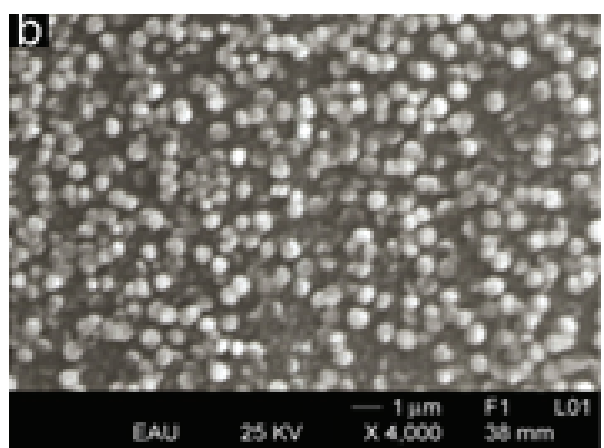

(b)

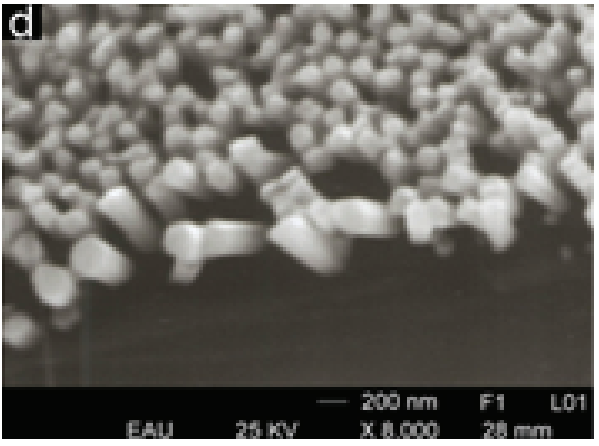

(d)

Figure 1: Typical SEM images of $\mathrm{ZnO}$ nanorods grown onto ordinary glass substrates at (a) $350^{\circ} \mathrm{C}$ (b) $450^{\circ} \mathrm{C}$ (c) $550^{\circ} \mathrm{C}$ and $(\mathrm{d}) 550^{\circ} \mathrm{C}$ with little amount of thiourea added.

the number of the nanorods and the width of the zinc oxide surface per unit area increased compared to those without thiourea. The molar ratio used for $\mathrm{ZnO}$ nanorods with thiourea is $1: 0.25(\mathrm{Zn}: \mathrm{tu})$, since it is optimal condition for the growing of the nanorods at the highest aspect ratio. Besides, it is known that the amount of thiourea in solution is extremely important factor which determines the final rods dimensions and its addition, generally, leads to the formation of thinner rods $[39,40]$. The possible mechanism in the morphological changes of the $\mathrm{ZnO}$ nanorods, which are produced from thiourea mixed $\mathrm{ZnCl}_{2}$, solution is reported in the literature that in some crystallization processes. The growth rate of a crystal facet can be inhibited by an impurity adsorption during the front growth and incorporation of new molecules into that facet. For example, widening of the crystal is restricted by the adsorption of $\mathrm{ZnS}$ particles as the facet of the crystals is reported [40, 41]. As a result of this, longitudinal length in c-axis has increased that deteriorates optical properties of the crystals.

Figure 2 shows the XRD pattern of the $\mathrm{ZnO}$ nanorods prepared in the absence and presence of thiourea. As shown in the XRD pattern, the peak of (002) is dominant in $\mathrm{ZnO}$ nanorods grown in the absence of thiourea. In the $\mathrm{ZnO}$ nanorods grown in the presence of thiourea, in addition to $\mathrm{ZnO}$ structures, emerging of second phases, like $\mathrm{ZnS}$, caused an increase in the peak count. Some of the reflections at $2 \theta=27.20,28.80$, and $30.80^{\circ}$ corresponding to Muller indices of 110,111 , and 200 detected in the XRD pattern can be attributed to the reflection of $\mathrm{ZnS}$ sphalerite phase

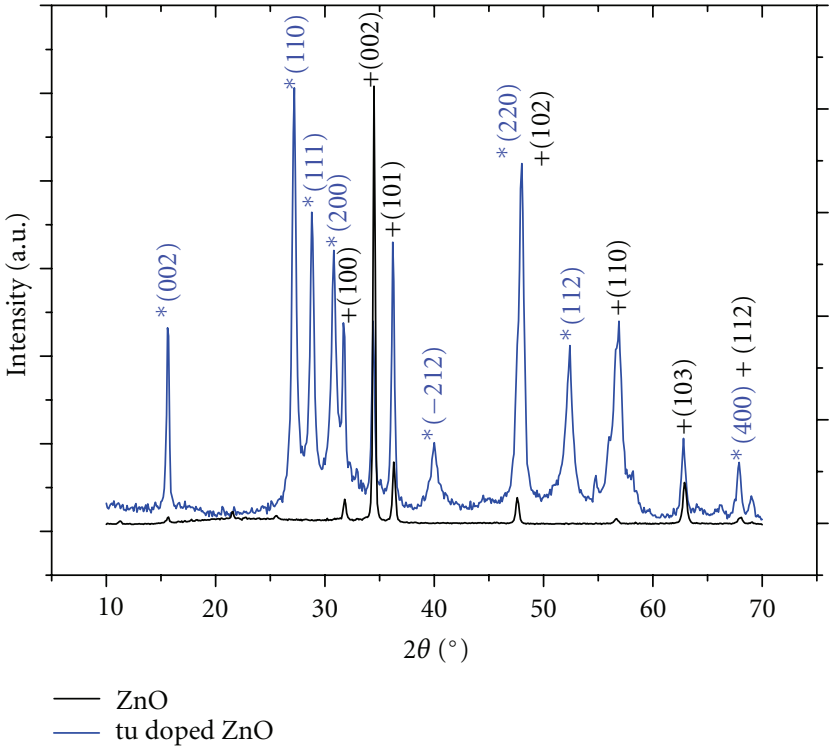

FIGURE 2: XRD patterns of $\mathrm{ZnO}$ nanorods.

in Figure 2, the $\mathrm{ZnCl}_{2}$ and thiourea in aqueous solution yield a complex structure of thiourea zinc with molecular formula $\mathrm{Zn}(\mathrm{tu})_{2} \mathrm{Cl}_{2}$, which decomposes to the formation of zinc sulfide at temperatures above $300^{\circ} \mathrm{C}$ (as it has been reported in [40]). Besides, the possible growth mechanism 


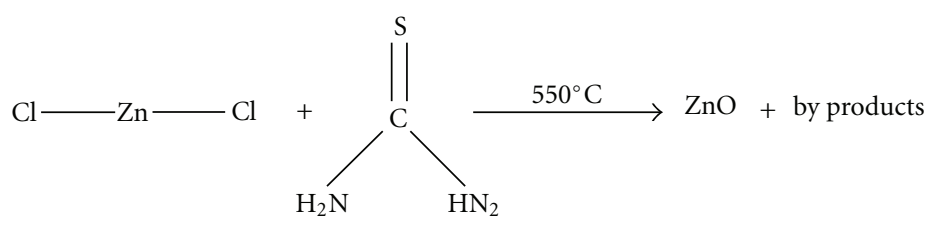

Scheme 1

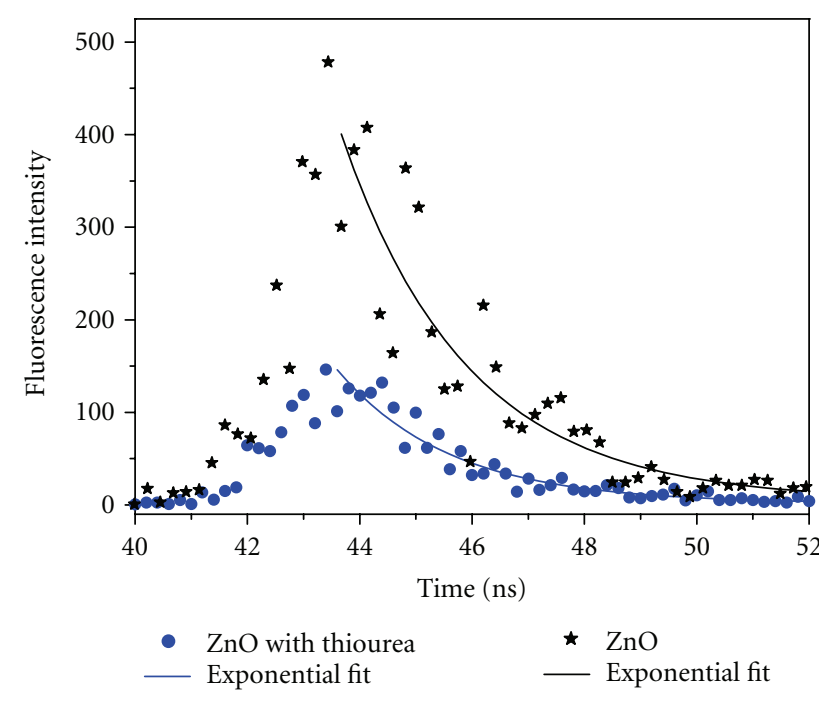

FIGURE 3: Fluorescence decay of $\mathrm{ZnO}$ nanorods with exponential fit.

for the formation of $\mathrm{ZnO}$ nanorods from the $\mathrm{ZnCl}_{2}$ solution with thiourea at $550^{\circ} \mathrm{C}$ can be shown in Scheme 1.

The quality of $\mathrm{ZnO}$ is commonly examined using timeresolved photoluminescence (TRPL) measurement as well as steady-state photoluminescence (PL). TRPL measurement provides significant information about the exciton lifetime, which represents efficiency of the radiative recombination. In order to determine the exciton lifetime of $\mathrm{ZnO}$ nanorods, the photoluminescence decay spectra of the samples were recorded at $337 \mathrm{~nm}$ excitation wavelength at room temperature. Next, the lifetime of the samples was calculated by using specific fit software that belongs to PTI (Photon Technology International). The obtained photoluminescence decay of $\mathrm{ZnO}$ nanorods were analyzed to single-, bi-, and three-exponential fits according to (1)

$$
I_{\mathrm{fl}}=\sum_{i} \alpha_{i} \exp \left(\frac{-t}{\tau_{i}}\right)
$$

where $i$ is the number of exponentials, and $\tau_{i}$ and $\alpha_{i}$ are the lifetime and the preexponential factor, for each components. The photoluminescence decay spectra of the samples with exponential fits were given in Figure 3. As a result of the exponential analyses, it was determined that the photoluminescence decay of $\mathrm{ZnO}$ nanorods indicates singleexponential fits with the acceptable $\chi^{2}$ values. Therefore, the single-exponential fit results for the evaluation of exciton lifetime of $\mathrm{ZnO}$ samples were used. The obtained single-exponential fit shows that $\mathrm{ZnO}$ nanorods also have a homogeny distribution onto the glass surface. The exciton lifetime of $\mathrm{ZnO}$ nanorods was determined as $\tau=1.56 \pm$ $0.05 \mathrm{~ns}\left(\chi^{2}=0.9\right)$, when that of $\mathrm{ZnO}$ nanorods containing thiourea was calculated as $\tau=2.12 \pm 0.03 \mathrm{~ns}\left(\chi^{2}=1.0\right)$. The calculated lifetime values revealed that the presence of thiourea in $\mathrm{ZnO}$ nanorods resulted in increasing the exciton lifetime, suggesting an enhancement in radiative recombination. As considered by the experimental results, it is clear that the changing in the exciton lifetimes is resulted from the presence of the morphological difference between pure $\mathrm{ZnO}$ nanorods and $\mathrm{ZnO}$ nanorods containing thiourea, since it is known that the different morphologies of $\mathrm{ZnO}$ nanostructure act a significant role in the exciton lifetimes [22]. Additionally, it is inferred that $\mathrm{ZnO}$ nanostructures doped with thiourea bring about growing goodquality nanorods. Tuning of the exciton lifetime of $\mathrm{ZnO}$ nanostructure, depending on morphology, is desirable result in nanotechnological applications.

\section{Conclusion}

A little addition of thiourea into $\mathrm{ZnCl}_{2}$ solution $\left(\mathrm{ZnCl}_{2}\right.$ : tu $=1: 0.25)$ provides thinner $\mathrm{ZnO}$ nanorods with the higher aspect ratio compared to that obtained from pure $\mathrm{ZnCl}_{2}$ solution. The diameter of the $\mathrm{ZnO}$ nanorods was decreased from $1000 \mathrm{~nm}$ to $500 \mathrm{~nm}$, while their lengths increased to about $200 \mathrm{~nm}$ by thiourea doping as seen by SEM images. At the same time, the number of the nanorods and the width of the zinc oxide surface per unit area increased. As a result of time-resolved photoluminescence studies, the lifetime of $\mathrm{ZnO}$ nanorods and $\mathrm{ZnO}$ nanorods containing thiourea was determined as $\tau=1.56 \pm 0.05 \mathrm{~ns}\left(\chi^{2}=0.9\right)$ and $\tau=2.12 \pm$ $0.03 \mathrm{~ns}\left(\chi^{2}=1.0\right)$, respectively. The results indicated that the exciton lifetime of $\mathrm{ZnO}$ nanorods containing thiourea increased through an increase in radiative recombination. It is clearly seen that the lifetime of $\mathrm{ZnO}$ nanorods is strongly dependant on the presence of the morphological differences between $\mathrm{ZnO}$ nanorods and $\mathrm{ZnO}$ nanorods containing thiourea. Summary, it is mentioned that the doping material prevents the nucleation of the sample and improves the exciton lifetime of synthesized $\mathrm{ZnO}$ nanorods. Discussion on the presented results in this study has a great potential for the application of $\mathrm{ZnO}$ in optoelectronic systems.

\section{References}

[1] M. Willander, O. Nur et al., "Zinc oxide nanorod based photonic devices: recent progress in growth, light emitting diodes and lasers," Nanotechnology, vol. 20, no. 33, Article ID 332001, pp. 1-40, 2009. 
[2] D. G. Thomas, "The exciton spectrum of zinc oxide," Journal of Physics and Chemistry of Solids, vol. 15, no. 1-2, pp. 86-96, 1960.

[3] D. M. Bagnall, Y. F. Chen, Z. Zhu, T. Yao, M. Y. Shen, and T. Goto, "High temperature excitonic stimulated emission from ZnO epitaxial layers," Applied Physics Letters, vol. 73, no. 8, pp. 1038-1040, 1998.

[4] M. H. Huang, S. Mao, H. Feick et al., "Room-temperature ultraviolet nanowire nanolasers," Science, vol. 292, no. 5523, pp. 1897-1899, 2001.

[5] A. B. Djurišić and Y. H. Leung, "Optical properties of $\mathrm{ZnO}$ nanostructures," Small, vol. 2, no. 8-9, pp. 944-961, 2006.

[6] Ü. Özgür, Y. I. Alivov, C. Liu et al., "A comprehensive review of $\mathrm{ZnO}$ materials and devices," Journal of Applied Physics, vol. 98, no. 4, Article ID 041301, pp. 1-103, 2005.

[7] S. Chen, Y. Liu, C. Shao et al., "Structural and optical properties of uniform $\mathrm{ZnO}$ nanosheets," Advanced Materials, vol. 17, no. 5, pp. 586-590, 2005.

[8] A. Tsukazaki, A. Ohtomo, T. Onuma et al., "Repeated temperature modulation epitaxy for p-type doping and light-emitting diode based on ZnO," Nature Materials, vol. 4, no. 1, pp. 4245, 2005.

[9] S. F. Chichibu, T. Onuma, M. Kubota et al., "Improvements in quantum efficiency of excitonic emissions in $\mathrm{ZnO}$ epilayers by the elimination of point defects," Journal of Applied Physics, vol. 99, no. 9, Article ID 093505, 2006.

[10] J. Koida, S. F. Chichibu, A. Uedono, T. Sota, A. Tsukazaki, and M. Kawasaki, "Radiative and nonradiative excitonic transitions in nonpolar $(112 \overline{2} 0)$ and polar $(0001 \overline{1})$ and (0001) Zno epilayers," Applied Physics Letters, vol. 84, no. 7, pp. 1079-1081, 2004.

[11] T. Koida, A. Uedono, A. Tsukazaki, T. Sota, M. Kawasaki, and S. F. Chichibu, "Direct comparison of photoluminescence lifetime and defect densities in $\mathrm{ZnO}$ epilayers studied by timeresolved photoluminescence and slow positron annihilation techniques," Physica Status Solidi A, vol. 201, no. 12, pp. 2841$2845,2004$.

[12] A. Teke, Ü. Özgür, S. Doğan et al., "Excitonic fine structure and recombination dynamics in single-crystalline $\mathrm{ZnO}$," Physical Review B, vol. 70, no. 19, Article ID 195207, pp. 1-10, 2004.

[13] X. H. Zhang, S. J. Chua, A. M. Yong et al., "Exciton radiative lifetime in $\mathrm{ZnO}$ nanorods fabricated by vapor phase transport method," Applied Physics Letters, vol. 90, no. 1, Article ID 013107, 2007.

[14] X. H. Zhang, S. J. Chua, A. M. Yong et al., "Exciton radiative lifetime in $\mathrm{ZnO}$ quantum dots embedded in SiOx matrix," Applied Physics Letters, vol. 88, no. 22, Article ID 221903, 2006.

[15] G. Xiong, U. Pal, and J. G. Serrano, "Correlations among size, defects, and photoluminescence in $\mathrm{ZnO}$ nanoparticles," Journal of Applied Physics, vol. 101, no. 2, Article ID 024317, 2007.

[16] N. C. Giles, C. Xu, M. J. Callahan, B. Wang, J. S. Neal, and L. A. Boatner, "Effects of phonon coupling and free carriers on band-edge emission at room temperature in n-type $\mathrm{ZnO}$ crystals," Applied Physics Letters, vol. 89, no. 25, Article ID 251906, 2006.

[17] A. B. Djurišić, Y. H. Leung, K. H. Tam et al., "Defect emissions in ZnO nanostructures," Nanotechnology, vol. 18, no. 9, Article ID 095702, 2007.

[18] W. M. Kwok, A. B. Djurišić, Y. H. Leung, W. K. Chan, and D. L. Phillips, "Time-resolved photoluminescence from $\mathrm{ZnO}$ nanostructures," Applied Physics Letters, vol. 87, no. 22, Article ID 223111, pp. 1-3, 2005.
[19] X. Zhou, Q. Kuang, Z. Y. Jiang et al., "The origin of green emission of $\mathrm{ZnO}$ microcrystallites: surface-dependent light emission studied by cathodoluminescence," Journal of Physical Chemistry C, vol. 111, no. 32, pp. 12091-12093, 2007.

[20] M. D. McCluskey and S. J. Jokela, "Sources of n-type conductivity in ZnO,” Physica B, vol. 401-402, pp. 355-357, 2007.

[21] Z. Qiu, K. S. Wong, M. Wu, W. Lin, and H. Xu, "Microcavity lasing behavior of oriented hexagonal $\mathrm{ZnO}$ nanowhiskers grown by hydrothermal oxidation," Applied Physics Letters, vol. 84, no. 15, pp. 2739-2741, 2004.

[22] Y. Zhong, A. B. Djurišić, Y. F. Hsu et al., "Exceptionally long exciton photoluminescence lifetime in $\mathrm{ZnO}$ tetrapods," Journal of Physical Chemistry C, vol. 112, no. 42, pp. 1628616295, 2008.

[23] J. Shi, J. Chen, Z. Feng et al., “Time-resolved photoluminescence characteristics of subnanometer $\mathrm{ZnO}$ clusters confined in the micropores of zeolites," Journal of Physical Chemistry B, vol. 110, no. 51, pp. 25612-25618, 2006.

[24] A. V. Kavokin, G. Malpuech, and W. Langbein, "Theory of propagation and scattering of exciton-polaritons in quantum wells," Solid State Communications, vol. 120, no. 7-8, pp. 259263, 2001.

[25] B. Gil and A. V. Kavokin, "Giant exciton-light coupling in $\mathrm{ZnO}$ quantum dots," Applied Physics Letters, vol. 81, no. 4, pp. 748750, 2002.

[26] S. Hong, T. Joo, W. Park, Y. H. Jun, and G. C. Yi, "Timeresolved photoluminescence of the size-controlled $\mathrm{ZnO}$ nanorods," Applied Physics Letters, vol. 83, no. 20, pp. 4157-4159, 2003.

[27] S. Musić, A. Šarić, and S. Popović, "Dependence of the microstructural properties of $\mathrm{ZnO}$ particles on their synthesis," Journal of Alloys and Compounds, vol. 448, no. 1-2, pp. 277283, 2008.

[28] W. I. Park, D. H. Kim, S. W. Jung, and G. C. Yi, "Metalorganic vapor-phase epitaxial growth of vertically well-aligned $\mathrm{ZnO}$ nanorods," Applied Physics Letters, vol. 80, no. 22, pp. 42324234, 2002.

[29] J. Y. Park, D. J. Lee, Y. S. Yun, J. H. Moon, B. T. Lee, and S. S. Kim, "Temperature-induced morphological changes of $\mathrm{ZnO}$ grown by metalorganic chemical vapor deposition," Journal of Crystal Growth, vol. 276, no. 1-2, pp. 158-164, 2005.

[30] J.-H. Park, Y.-J. Choi, W.-J. Ko, I.-S. Whang, and J.-G. Park, "ZnO nanorods grown by a pulsed laser deposition process," Materials Research Society Symposium Proceedings, vol. 848, Article ID FF9.7, pp. 421-426, 2005.

[31] Z. W. Liu, C. K. Ong, T. Yu, and Z. X. Shen, "Catalystfree pulsed-laser-deposited $\mathrm{ZnO}$ nanorods and their roomtemperature photoluminescence properties," Applied Physics Letters, vol. 88, no. 5, Article ID 053110, pp. 1-3, 2006.

[32] Y. C. Wang, I. C. Leu, and M. H. Hon, "Preparation of nanosized $\mathrm{ZnO}$ arrays by electrophoretic deposition," Electrochemical and Solid-State Letters, vol. 5, no. 4, pp. C53-C55, 2002.

[33] M. J. Zheng, L. D. Zhang, G. H. Li, and W. Z. Shen, "Fabrication and optical properties of large-scale uniform zinc oxide nanowire arrays by one-step electrochemical deposition technique," Chemical Physics Letters, vol. 363, no. 1-2, pp. 123$128,2002$.

[34] M. H. Huang, Y. Wu, H. Feick, N. Tran, E. Weber, and P. Yang, "Catalytic growth of zinc oxide nanowires by vapor transport," Advanced Materials, vol. 13, no. 2, pp. 113-116, 2001. 
[35] N. Pan, X. Wang, K. Zhang et al., "An approach to control the tip shapes and properties of ZnO nanorods," Nanotechnology, vol. 16, no. 8, pp. 1069-1072, 2005.

[36] H. Zhu, D. Yang, and H. Zhang, "A simple and novel low-temperature hydrothermal synthesis of $\mathrm{ZnO}$ nanorods," Inorganic Materials, vol. 42, no. 11, pp. 1210-1214, 2006.

[37] F. Li, Z. Li, and F. J. Jin, "Structural and luminescent properties of $\mathrm{ZnO}$ nanorods prepared from aqueous solution," Materials Letters, vol. 61, no. 8-9, pp. 1876-1880, 2007.

[38] L. Vayssieres, "Growth of arrayed nanorods and nanowires of ZnO from aqueous solutions," Advanced Materials, vol. 15, no. 5, pp. 464-466, 2003.

[39] E. Sonmez, T. Karacali, A. E. Ekinci, and M. Ertugrul, "Optical properties of $\mathrm{ZnO}$ nanorods on glass via spray deposition of solution containing zinc chloride and thiourea," IEEE Transactions on Nanotechnology, vol. 10, no. 3, pp. 532-536, 2011.

[40] T. Dedova, O. Volobujeva, J. Klauson, A. Mere, and M. Krunks, "ZnO nanorods via spray deposition of solutions containing zinc chloride and thiocarbamide," Nanoscale Research Letters, vol. 2, no. 8, pp. 391-396, 2007.

[41] T. Schilling and D. Frenkel, "Self-poisoning of crystal nuclei in hard-rod liquids," Journal of Physics Condensed Matter, vol. 16, no. 19, pp. S2029-S2036, 2004. 

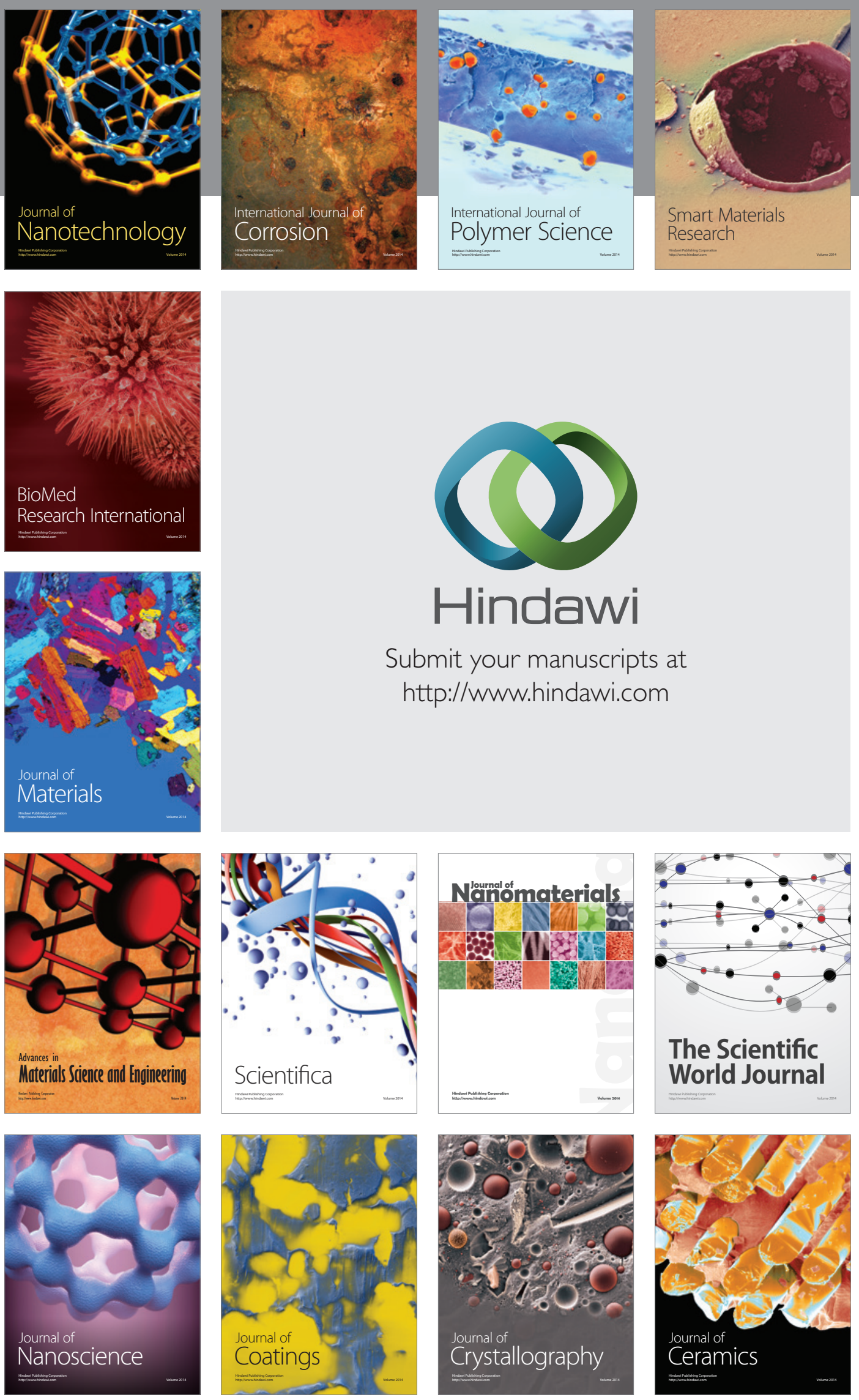

The Scientific World Journal

Submit your manuscripts at

http://www.hindawi.com

\section{World Journal}

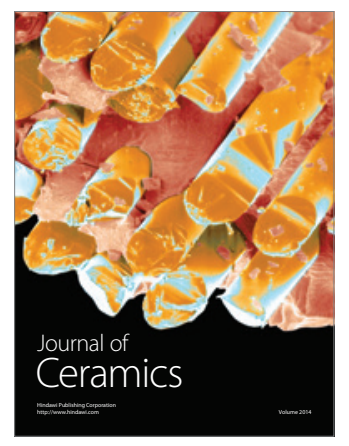

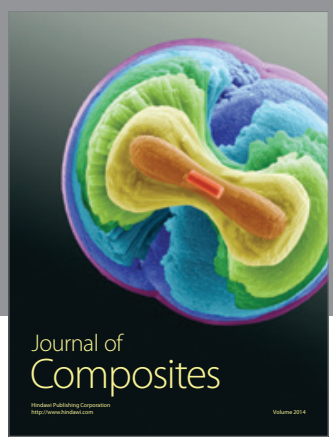
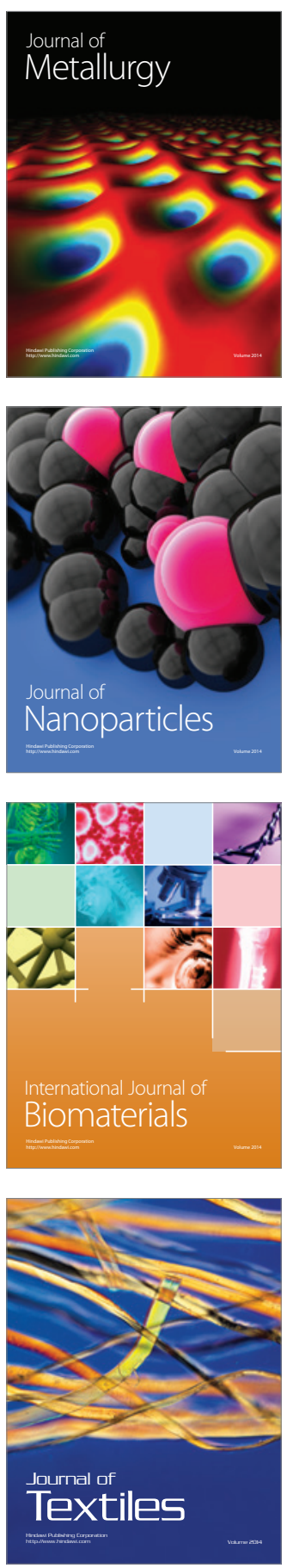